\title{
EXPERIÊNCIAS INTERSECCIONAIS COTIDIANAS: UM ENCONTRO ENTRE MULHERES NEGRAS E PERIFÉRICAS
}

DAILY INTERSECTIONAL EXPERIENCES:

A MEETING BETWEEN BLACK AND PERIPHERAL WOMEN

\section{EXPERIENCIAS INTERSECCIONALES COTIDIANAS: UNA REUNIÓN ENTRE MUJERES NEGRAS Y PERIFÉRICAS}

Danielle Christina do Nascimento Oliveira ${ }^{1}$

\section{RESUMO}

O presente trabalho é parte de uma pesquisa em andamento, que busca dialogar com novas histórias de pertencimento e emancipação a partir de experiências interseccionais cotidianas baseadas no feminismo negro diaspórico. Tendo como objetivos problematizar os impactos, as tensões, os conflitos e as negociações que as diversas redes educativas produzem a partir da naturalização do racismo. Este trabalho, narra a trajetória de mulheres negras a partir do "encontro" - utilizado também como metodologia - delas com/na Universidade pública. Fazendo-se necessário repensarmos o quão importante são esses espaços, sobretudo para a população negra e periférica. Por fim, traz algumas tensões e negociações vivenciadas pelas protagonistas, para permanecerem neste espaço formativo; e busca contribuir com a produção e socialização dos conhecimentos/saberes afrodiaspóricos, trazendo reflexões acerca do protagonismo e dos processos identitários de mulheres negras.

PALAVRAS-CHAVE: Mulheres negras. Processos identitários. Espaços formativos.

\section{ABSTRACT}

The present work is part of an ongoing research that seeks to dialogue with new stories of belonging and emancipation from everyday intersectional experiences based on diasporic black feminism. Having as objectives to problematize the impacts, tensions, conflicts and negotiations that the various educational networks produce from the naturalization of racism. This paper narrates the trajectory of black women from the "meeting" - also used as a methodology - of them with the public University. It is necessary to rethink how important these spaces are, especially for the black and peripheral population. Finally, it brings some tensions and negotiations experienced by the protagonists, to remain in this formative space; and seeks to contribute to the production and

Submetido em: 30/08/2019 - Aceito em: 21/10/2019 - Publicado em: 28/12/2019.

${ }^{1}$ Estudante de Mestrado do Programa de Pós-Graduação em Educação da Universidade do Estado do Rio de Janeiro (ProPEd/UERJ). Bolsista de Mestrado do CNPq. Graduada em Pedagogia pela Faculdade de Educação da Universidade do Estado do Rio de Janeiro (UERJ). Pesquisadora com interesses em educação e relações étnicorraciais, incluindo as discussões de gênero e sexualidade ancoradas à perspectiva do feminismo negro a partir do processo identitário da afrodiáspora. Participa do Grupo de Pesquisas "Culturas e Identidades no Cotidiano", na linha dos "Cotidianos, Redes Educativas e Processos Culturais". 
socialization of aphrodiasporic knowledge, bringing reflections on the protagonism and identity processes of black women.

KEYWORDS: Black women Identity processes. Formative spaces.

\section{RESUMEN}

El presente trabajo es parte de una investigación en curso que busca dialogar con nuevas historias de pertenencia y emancipación de las experiencias interseccionales cotidianas basadas en el feminismo negro diaspórico. Tener como objetivos problematizar los impactos, tensiones, conflictos y negociaciones que las diversas redes educativas producen a partir de la naturalización del racismo. Este artículo narra la trayectoria de las mujeres negras de la "reunión", también utilizada como metodología, de ellas con la universidad pública. Es necesario repensar cuán importantes son estos espacios, especialmente para la población negra y pobre. Finalmente, trae algunas tensiones y negociaciones experimentadas por las protagonistas, para permanecer en este espacio formativo; y busca contribuir a la producción y socialización del conocimiento afrodisporico, trayendo reflexiones sobre el protagonismo y los procesos de identidad de las mujeres negras.

PALABRAS CLAVE: Mujeres negras Procesos de identidad. Espacios formativos.

\section{INTRODUÇÃO}

O ano era 2015, e a Baixada Fluminense no Estado do Rio de Janeiro foi uma das áreas mais afetadas inicialmente por conta da crise financeira do Estado. O que já era precário ficou ainda pior. O desemprego aumentou e em algumas escolas e hospitais públicos começaram a faltar materiais, atrasar pagamentos e até fechar as portas. E, em 2016 o governo do Estado do Rio de Janeiro decretou "estado de calamidade pública devido à crise"2, todas as áreas estavam indo de mal a pior, o "projeto" elaborado para derrubar a presidência estava caminhando a passados largos, e acarretou no impeachment da presidenta Dilma Rousseff - golpe de 2016. A população pedia socorro com tamanha desesperança em relação ao novo governo. Ministérios foram destituídos e até findados, projetos que levaram anos para serem colocamos em prática de forma sólida e consciente foram engavetados. Retrocedemos! As áreas da saúde e educação foram as mais prejudicas, sobretudo no tocante a Cultura e Pesquisa do país.

\footnotetext{
${ }^{2}$ Matéria do Jornal “O globo". Disponível em: <http://g1.globo.com/rio-de-janeiro/noticia/2016/06/governo-dorj-decreta-estado-de-calamidade-publica-devido-crise.html>. Acesso em: 14 jul. 2019.
} 
A Universidade do Estado do Rio de Janeiro (UERJ), foi/é uma das mais atingidas por esse "projeto de desmonte da educação pública", e, sem dúvida os estudantes de baixa renda foram os mais afetados. Sendo a UERJ pioneira em programas públicos e sociais que transformaram a realidade brasileira, como as Ações Afirmativas para ingresso e permanência de estudantes negros, indígenas, periféricos e de baixa renda no ensino superior, com intuito de democratizar o acesso à educação pública, gratuita e de qualidade, se viu sem saber o que fazer para não perder esses estudantes que usufruem de seus direitos a tão pouco tempo - desde os anos 2000 com a reserva de vagas ${ }^{3}$. Grande parte desses estudantes, sobretudo aqueles que além da bolsa permanência (oriunda do ingresso pelo sistema de cotas) ainda possuía bolsa de extensão, iniciação cientifica ou iniciação à docência, e assim eram "impedidos de trabalhar fora da universidade" devido a carga horária etc., precisaram procurar trabalhos outros que os ajudassem a se manter naquele espaço durante os atrasos das bolsas.

E, foi nesse momento de caos, que surgiu esse projeto de pesquisa. Em um período, onde só era possível para alguns estudantes e funcionários permanecerem na Universidade pública através de doações e/ou "gambiarras" (FERNANDES, 2019), tais como: vendas de doces, salgadinho e acessórios pelos corredores e dentro dos (poucos) elevadores que estavam funcionando; ofertando aulas particulares dentro e fora do campus; e, participando de rodas de conversas e fortalecimento. Apesar de todas as dificuldades, a UERJ estava viva, e seguiu se reinventando e resistindo com a ajuda de todos e todas, sobretudo das mulheres. Sobre isso, Marielle Franco ${ }^{4}$ (2017), através das suas vivências e pesquisas, nos informa que:

\footnotetext{
${ }^{3}$ Ver as Leis: $n^{\circ} 3.524 / 2000, n^{\circ} 3.708 / 2001, n^{\circ} 4.151 / 2003, n^{\circ} 5.074 / 2007, n^{\circ} 5.346 / 2008$ e $n^{\circ} 8.121 / 2018$. Disponível em: <http://www.uerj.br/a-uerj/a-universidade/sistema-de-cotas/>. Acesso em: 14 jul. 2019.

${ }^{4}$ Eleita Vereadora da Câmara Municipal do Rio de Janeiro pelo PSOL. Mulher, negra, mãe, favelada, socióloga formada pela PUC-Rio e mestra em Administração Pública pela Universidade Federal Fluminense (UFF). Sua dissertação de mestrado teve como tema: "UPP: a redução da favela a três letras". Marielle Franco foi a quinta vereadora mais votada no Rio de Janeiro nas eleições de 2016, com 46.502 votos. Iniciou sua militância em direitos humanos após ingressar no pré-vestibular comunitário e perder uma amiga, vítima de bala perdida, num tiroteio entre policiais e traficantes no Complexo da Maré. Ao se tornar mãe, ela também começou a se constituir como lutadora pelos direitos das mulheres e debater essa temática na periferia. As questões do feminismo, da luta contra o racismo, bem como a defesa dos direitos humanos nas favelas do país modulam o perfil de seu mandato e seus projetos em busca de um modelo de cidade mais justo para todos e todas. Trabalhou em organizações da sociedade civil, como a Brasil Foundation e o Centro de Ações Solidárias da Maré (Ceasm). Coordenou a Comissão de Defesa dos Direitos Humanos e Cidadania da Assembleia Legislativa do Rio de Janeiro (Alerj), ao lado de Marcelo
} 
Predominam nas favelas e na periferia, mulheres com essas características que, no entanto, são potência de criatividade, inventibilidade e superações das suas condições, nas formas de vida e nas organizações sociais em seus territórios, e alcançam em seus múltiplos fazeres centralidade na cidade (p. 90).

Por esse motivo, o trabalho relata algumas experiências a partir da explanação de algumas trocas entre mulheres negras e periféricas, oportunizadas por "encontros" (PASSOS, 2014) cotidianos, que possibilitaram tensionamentos relevantes para os estudos contemporâneos. Nossas principais interlocutoras para este trabalho, fazem uso dos nomes fictícios por questões éticas da pesquisa, e, exigidos e escolhidos por elas: Dandara Nascimento e Luísa Conceição - homenageando o matriarcado de suas famílias e heroínas negras brasileiras $^{5}$-, trazendo já nesse primeiro momento algumas questões bastante pertinentes para pensarmos sobre: Por que precisamos usar nomes fictícios para contar a história dessas mulheres? Por que elas se sentem mais à vontade preservando o anonimato? Não sendo essa só uma questão ética de pesquisa, e junto destas indagações, consequentemente tantas outras também surgem ao longo da pesquisa.

Muitas mulheres, após o encontro com a universidade pública, passam por alguns processos de descobertas, e uma delas tem sido as descobertas identitárias, como o "tornar-se negra" (SOUZA, 1983), a partir da consciência histórico racial que tem ocorrido através de experiências e vivências individuais e coletivas - espaços de formação -, afinal, para muitas essa foi (talvez) a primeira oportunidade de ocupar outros espaços de valorização e ressignificações de conhecimentos/saberes e identidades, seja como estudantes ou trabalhadoras deste local. Para Dandara e Luísa, estar no espaço acadêmico, é um sonho realizado, porque elas sabem que esse é um espaço privilegiado, de socialização e aprendizados continuo.

Elas se cruzaram a primeira vez na saída da estação do MetrôRio - Pavuna, enquanto caminhavam sentido ao ponto de ônibus. Após alguns encontros, Luísa - funcionária

Freixo. Foi assassinada brutalmente no dia 14 de Março de 2018, e até a presente perguntamos incessantemente "Quem matou Marielle? Quem matou Anderson e tantos outros?". Ver referências bibliográficas.

5 Heroínas negras brasileiras: Dandara dos Palmares, que resistiu em Maceió-AL, e Luísa Mahin, que resistiu em Salvador-BA. Ver referências bibliográficas. 
terceirizada de uma universidade pública na Zona Sul -, sugeriu a Dandara - estudante cotista de uma universidade pública da Zona Norte -, que marcassem um ponto de encontro diária na estação do MetrôRio - Pavuna, tendo em vista que as duas tinham como destino final/saltavam em estações diferentes, mas iniciavam o dia vindo de locais próximos, na Baixada FluminenseRJ. No auge da crise, elas buscaram estratégias para resistirem e não desistirem deste local tão almejado. Luísa, vinda de outro estado, é mãe de 5 filhos, solteira, diz que sonha em ver a filha mais nova formada por uma universidade pública, mas não disfarça o medo que sente dela resolver seguir os caminhos da irmã mais velha. Ela vê em Dandara uma esperança, tendo em vista que ela se parece com sua filha caçula. Sobre os filhos mais velhos, ela pouco fala, apenas informa que eles: "meteram o pé de casa, e foram ganhar o mundo". Com o atraso dos pagamentos de salário, ela passou a fazer bolo de pote para vender na rua e no trabalho.

Já Dandara, perdeu o pai ainda na infância e mora com sua mãe que é dona de casa. Mas, assim como Luísa, a mãe dela também sempre incentivou os estudos, mesmo não tendo cursado o ensino superior, desejava que ela cursasse. Com o atraso das bolsas acadêmicas (permanência, extensão, iniciação cientifica e iniciação à docência), Dandara começou a revender (dentro e fora da universidade), junto com a sua irmã, acessórios femininos. Inicialmente eram apenas bolsas e lingeries, mas muitas clientes após comprarem lingerie, perguntavam se também tinhamos algum "produtinho" para usarem junto da lingerie. Comprar uma roupa intima é algo tão íntimo que as deixavam a vontade para contar suas experiências sexuais, e até suas expectativas com a nova roupa. Esses momentos se tornaram tão comuns, e também necessários para a finalização das vendas e fidelização das clientes, que elas criaram um grupo "anônimo" no WhatsApp como um espaço virtual de trocas de experiências, dúvidas e dicas, e também como forma de divulgar os produtos. A partir disso, as vendas aumentaram muito, e foram 


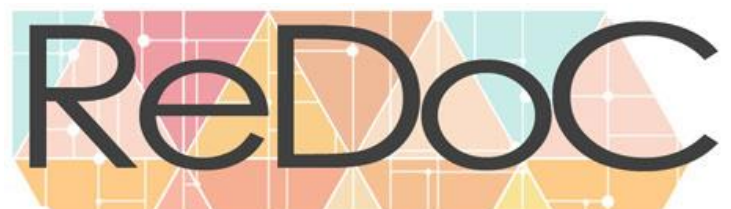

\section{Revista Docência e Cibercultura}

surgindo outras demandas, tais como: produtos caracterizados como de higiene pessoal, perfumaria e, cosméticos sensuais e eróticos ${ }^{6}$. Era um novo mundo a ser explorado.

Luísa além de parceira de viagem, se tornou também cliente - consumidora final. Com a chegada dos novos produtos, as vendas aumentaram, mas novas questões também emergiram, como por exemplo: Por que ainda é um tabu falar sobre sexo e sexualidade, sobretudo entre as mulheres?; Por que algumas preferem comprar produtos "escondidas" e outras dizem não precisar de nada disso?; Por que em um grupo "anônimo" elas se sentem a vontade para contar suas experiências?; Por que muitas mulheres não tem coragem de ir ao sex shop? Segundo uma pesquisa realizada pela Sociedade Brasileira de Empresas do Mercado Erótico e Sensual (Abeme), os brasileiros estão buscando cada vez mais novidades quando o assunto é a vida íntima, e o mercado audiovisual tem ajudado através do investimento em filmes populares que despertam a curiosidade e o desejo dos telespectadores, como a trilogia do americano 50 Tons de Cinza (2015, 2017, 2018), que narra a história de Anastasia Steele objeto de submissão do sadomasoquista Christian Grey; e o brasileiro De Pernas Pro Ar (2010, 2012, 2019), que narra a história de Alice Segretto na descoberta do seu próprio prazer e a expansão do mercado erótico. E,

De acordo com os últimos dados da instituição, divulgados em 2017, existem no país atualmente 11 mil pontos de vendas de produtos eróticos. Além disso, o setor é responsável atualmente por gerar mais de 100 mil empregos diretos ou indiretos. Grande parte desse sucesso tem ocorrido porque o mercado está se profissionalizando. A Abeme em parceria com as fábricas e empresários estão cada vez mais preocupados com a qualidade dos produtos disponibilizados, que precisam apresentar benefícios tanto para a vida íntima quanto para a saúde do consumidor. (EXAME, 13 abr. 2017).

As viagens de metrô delas duas nunca mais foram as mesmas. Sentindo-se acolhida de alguma forma, Luísa não hesitou em contar sobre sua vida: Eu perdi minha virgindade com 12 anos, meu tio tinha quase 20. Eu não queria, mas depois comecei a gostar dele. Na época não

\footnotetext{
${ }^{6}$ Tais como, os produtos das marcas: Pessini, Feitiços Aromáticos, Adão \& Eva Toys, A Sós, Intt Cosméticos e Hot Flowers. Produtos clinicamente e ginecologicamente testados, certificados pela ANVISA. Disponível em: < http://portal.anvisa.gov.br/>. Acesso em: 08 jun. 2019.
} 


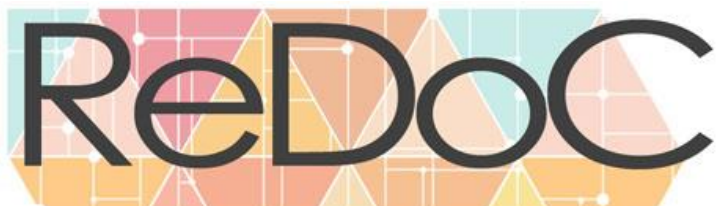

Revista Docência e Cibercultura

tinha esses produtos, eu senti muita dor, mas ele dizia que era assim mesmo. Depois disso ele falou para os amigos que eu não era mais moça, e eu tive que ficar com eles. Quando minha mãe descobriu, ela me bateu e disse que a culpa era minha, porque eu ficava me mostrando para os rapazes. Mas eu quase não ficava na rua. Eles soltavam pipa com meu tio e depois vinham atrás de mim. Tinha um que sempre me beijava antes e falava que casaria comigo quando eu crescesse; o outro era até bonitinho, mas já chegava botando a mão entre as minhas pernas; e tinha o "magrinho", ele falava muita besteira e estava sempre fumando cigarro. Eu sempre sentia dor, mas achava que era normal. Minha mãe mandou eu vir morar na casa da minha tia no Rio. Assim que eu cheguei, um senhor me convidou para dançar no grupo dele, mas minha tia não deixou. Ele insistiu durante uns meses... Sempre dizendo "minha mulatinha ainda vai ser passista de escola de samba”. Ele dizia que eu era a mulata mais linda do bairro. Claro que eu não acreditava nele, mas ficava feliz porque ele sempre me dava bombom: "Um bombom para o meu bombom marrom"; Meu corpo era todo certinho antes de eu engravidar.

Dialogando com tais narrativas de vida, o trabalho busca compreender melhor questões que permeiam toda a construção da nossa sociedade e as contradições que nos formam. O Brasil é um país altamente sexualizado, tendo bastante exposição de mulheres como objetos sexuais, sobretudo nas representações midiáticas, tais como revistas, telenovelas, videoclipes, filmes, letras de músicas dentre outros, e sendo a mulher negra quem mais sofre com a hipersexualização, vide a "mulata do carnaval". Sobre isso, Nascimento (2016) nos informa que na década de 70, houve um Manifesto das Mulheres Negras para denunciar a herança deixada pelos portugueses:

As mulheres negras receberam uma herança cruel: ser o objeto de prazer dos colonizadores. $\mathrm{O}$ fruto deste covarde cruzamento de sangue é o que agora é aclamado e proclamado como o "único produto nacional que merece ser exportado": a mulata brasileira'. Mas se a qualidade do "produto" é dita ser alta, o tratamento que ela recebe é extramemente degradante, sujo e desrespeitoso. (p. 74).

Para Luísa, ser esteticamente comparada com uma passista de escola de samba, e ser chamada de "mulata" é visto como um elogio, porque até então ela desconhecia o significado desta palavra. E, sobre essas questões, a youtuber e criadora do canal "Afro e Afins", Nátaly 


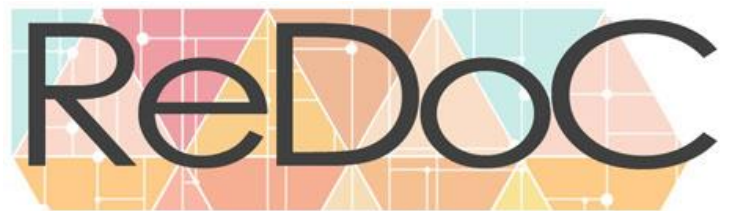

Revista Docência e Cibercultura

Neri - formada em Ciências Sociais pela Universidade Federal de São Paulo - UNIFESP -, traz discussões semanais sobre consumo consciente e autônomo, racismo e empoderamento feminino, ancorados aos conhecimentos acumulados e constantemente atualizados em sua militância que também perpassam pela universidade. Através de sua participação no TEDx São $\mathrm{Paulo}^{7}$, com o vídeo intitulado "A mulata que nunca chegou” (2016), na narrativa transcrita a seguir, Neri problematiza o racismo estrutural que desde a infância determina lugares e funções para as mulheres negras.

Eu sempre fui considerada uma menina feia. Pelo menos por mim, ou pela maioria das pessoas à minha volta. Meus pais, no caso, eram os únicos que realmente apreciavam esta beleza singular. Apesar de sempre ter tido uma autoestima muito baixa, como toda criança negra, com essa idade, existia um grupo específico de pessoas que me tratava de uma forma diferente. Com essa idade, existia um grupo de pessoas que, de fato, sabia que eu era uma menina não muito bonita, meio desajeitada, desengonçada... mas que também sabiam que, de alguma forma, eu me tornaria uma mulher muito bonita quando eu crescesse. Esse grupo de pessoas era formado majoritariamente por homens; homens mais velhos. Geralmente primos de segundo grau, amigos de primos de segundo grau, ou, então, desconhecidos. Que quando estavam na rua com meu pai, atrás de um balcão, devolvendo o dinheiro do troco do almoço, falavam pra ele: "Nossa, a sua filha é linda, vai dar muito trabalho quando crescer. [...] Como eles entendiam que uma menina que não se esforçava em nada pra ser sensual, pra ser bonita, que não sabia sobre maquiagem, sobre decote, que era só uma criança, como eles sabiam que essa criança feia daria trabalho? Essa foi uma das perguntas que eu sempre fiz ao longo da minha vida. Por que eu me vejo feia, por que as pessoas me veem feia, mas por que existe uma parcela masculina que tem certeza que eu serei bonita? De onde sai isso? Eu comecei a me perguntar e eu passei a deixar de me questionar, porque eu me sentia feia, então era melhor alguém falar: "Nátaly, você é feia, mas você pode se tornar bonita", do que alguém falar: "Nátaly, você vai ser sempre feia". (Grifo nosso).

Ela segue nos informando que ainda na adolescência, assim como para Luísa e tantas outras mulheres negras, ser chamada de mulata era como um elogio, era a expectativa de "um corpo aceitável” aos olhos de todos, e principalmente dos homens.

Foi com uns 11, 12 anos que eu entendi o que eu era. Eu entendi que eu era mulata. Eu entendi que as pessoas me tratavam e me viam como a mulata. E o que era a mulata

\footnotetext{
${ }^{7}$ A TEDx Brasil é uma versão independente de uma das conferências mais importantes e inovadoras do mundo, a TED - Technology, Entertainment, Design. Essa é uma ONG criada nos EUA, em 1984, e ela tem o intuito de propagar "ideias que merecem ser compartilhadas". Nas convenções TED, realizadas oficialmente duas vezes por ano, são convidados empreendedores e pensadores de todo o mundo para darem palestras curtas. A plateia é limitada e bastante concorrida, já que grandes mentes do planeta discursarão no dia. Disponível em: <https://tedxsaopaulo.com.br/>. Acesso em: 20 jun. 2019.
} 
naquela época? Naquela época, pra mim, mulata era uma categoria menos pior de negra. [...] "Sorte minha que eu não sou tão preta. Deus não me fez branca, me entristeço por isso, mas obrigada por ter me feito mulata. É um sofrimento a menos". Com meus 13, 14, 15 anos, por aí, eu comecei a entender o que a mídia, o que a sociedade dizia sobre o que era a mulata. Eu comecei a entender que ser mulata não era tão ruim. Que ser mulata era ser da cor do pecado, que ser mulata era ter curvas envolventes, sensuais, que a mulata me colocava na poesia, que a mulata colocava o meu corpo na bossa-nova. Eu não era "a mulata", mas me tornaria a mulata. E era a expectativa de que meu corpo se desenvolvesse, que as curvas aparecessem e eu pudesse, enfim, ser a mulher que sambava, fazia com que eu recebesse elogios. Esses eram os únicos. Eu aceitei... Me chamavam de mulata, sabe: mulata, de "mula"... que é um híbrido... de cavalo e jumenta. Foi um termo que foi cunhado no passado colonial pra classificar os filhos feitos dos estupros cometidos pelos donos das casas grandes, nas negras escravizadas. E que, hoje em dia, é um termo racista que caracteriza mulheres negras de pele clara, magras, porém curvilíneas e que, com certeza, por uma "determinação biológica", sabem sambar, afinal, está no sangue saber sambar. Com 16, 17 anos, eu fiquei esperando a mulata. "Ah, cadê a mulata? Falaram a vida inteira que a mulata ia chegar, tô aqui esperando essa mulata..."; [...] E o único elogio que ouvi minha vida inteira é que eu só seria bonita no dia em que meu corpo se desenvolvesse e eu efetivasse a mulata, então cadê a mulata? Eu esperei a mulata, e aí a mulata não foi aparecendo. A mulata não vinha, eu ficava preocupada, minhas amigas peitudas, bundudas, e eu ainda reta, eu falava: "Cadê essa bosta dessa mulata que me prometeram a vida inteira?" Cadê a minha autoestima que estaria com ela? Cadê a única expectativa de amor-próprio que eu coloquei dentro de uma bunda e de um peito? Que me prometeram durante toda a minha vida? "Ela vai ser muito bonita, ela vai sambar... ela vai rebolar, ela vai ter um corpo de dar inveja, porque ela é uma mulata, e mulata é menos pior". Eu esperei a mulata, a mulata não apareceu, e aqui está eu hoje. $\quad$ Meu corpo parou de se desenvolver aos 13 anos. Com 13 anos eu não cresci mais, não me desenvolvi fisicamente, então com 13 anos eu comecei a entrar em pânico. Com 15 anos, eu estava desesperada. E comecei a perceber que, de fato, a mulata não chegaria, e que eu precisaria compreender e achar outras formas de lidar com meu corpo. (Grifo nosso).

Diferente de Neri, que não teve o corpo muito modificado ao decorrer dos anos, Luísa não só teve o corpo desenvolvido como o esperado para ser tratada como "mulata" - "pronto" para a realização dos sonhos de ser dançarina, passista e desejada pelos homens -, como teve também o corpo modificado após uma gravidez precoce e indesejada, que a impediu de continuar sonhando com os "benefícios de ser mulata" e a fizeram odiar o próprio corpo. Traumas causados por gravidez de risco, complicações durante o parto, violências obstétricas, e negligencias médicas em hospitais públicos na Baixada Fluminense. Ainda com 17-18 anos seu corpo já havia se modificado bastante, e nessa mesma idade Nátaly Neri nos informa que, 
Passei a odiar o meu corpo, porque a mulata não veio. Então, não tinha nada que me salvasse, não tinha expectativas de melhoras. Eu odiava o meu corpo. Eu odiava quem eu era de uma forma muito profunda, a ponto de me bater em noites de crise, quando eu estava mal. A ponto de esmurrar os meus próprios seios porque eles não cresceram o tanto que as pessoas diziam que deveriam ter crescido. [...] Como eu, uma adolescente, tão dentro do meu tempo, tão fruto da minha época, que lia revistas femininas, que via TV, que via novela, que sabia que o ideal era o corpo magro; como consegui odiar o meu corpo magro? Como eu consegui odiar um corpo que era padronizado? Como eu consegui odiar um corpo que era valorizado? Como eu consegui odiar um corpo que em todos os espaços diziam que era o melhor? Eu odiava o meu corpo magro. E por quê? Seria por que... os mecanismos do racismo são muito mais complexos e muito mais profundos do que qualquer padrão de beleza? Será que odiei o meu corpo magro porque, de alguma forma, o fato de ter inferiorizado pessoas por conta de seus traços e de suas origens culturais, ao longo da história, valeu mais do que padrões de beleza que se transformam ao longo do tempo; será que é isso? Será que racismo, de fato, é uma coisa séria? (Grifo nosso).
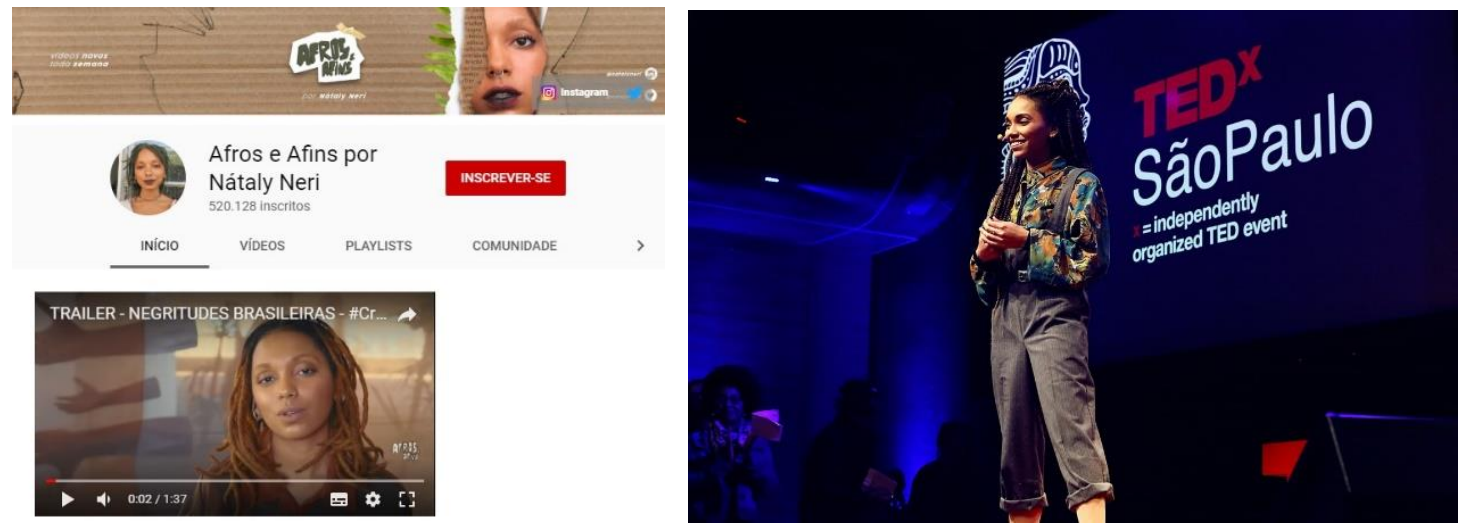

Figura 1 e 2. Nátaly Neri

Fonte: Imagens da página pública Afros e Afins, jan. 20178.

[...] Existem mulheres em que a mulata chega. E quando a mulata chega, o que acontece? Quando a bunda chega, quando o peito chega, o que acontece com essas mulheres? Elas pedem pra nunca ter nascido, porque elas não suportam a forma como são tratadas, porque elas não suportam a forma como são objetificadas o tempo inteiro, em todas suas relações, em todos seus espaços. Quando a mulata chega, é insuportável, porque elas não conseguem andar na rua, porque elas não conseguem conversar com pessoas sem sentir o desconforto dos olhares, das piadas direcionadas aos seus corpos. Quando a mulata chega, essas mulheres pedem a Deus: "Por que você me fez mulata?" E eu pedia pra Deus: "Por que não me faz mulata?" Então, qual é a diferença? A diferença é que racismo é estrutura. E ele vai fazer com que você se odeie. Com que você odeie o seu corpo, a sua vida, as suas origens, independente

\footnotetext{
${ }^{8}$ Vídeo disponível em: <https://www.youtube.com/watch?v=02TBfKeBbRw>. Acesso em: 28 jul. 2019.
} 
de quem você seja, basta ser negro. Você pode ser magro, você pode ser gordo, você pode ser rico, você pode ser pobre, você pode ser intelectual, você pode ser analfabeto. A senzala está pra todo mundo. De maneira, talvez, mais intensa pra uns do que pra outros, mas a senzala está aqui. A senzala está quando odeio meu corpo, quando odeio a minha realidade, quando odeio quem eu sou, pra corresponder a um estereótipo de beleza dessa sociedade escravocrata atual. Se o racismo não mata na entrada, ele faz com que você queira morrer na saída. Se o racismo... destrói de maneira clara e descarada, a negra de pele retinta, preta, escura, o racismo, fala meu nome como forma de amor: "mulata, bonita, sensual...", e depois me esfaqueia pelas costas. Parafraseando Augusto dos Anjos, "o racismo escarra na minha boca enquanto me beija". A gente não precisa de senhor de engenho, a gente não precisa de chibatada brutal nos nossos corpos, porque a senzala ainda é aqui nas nossas mentes, de maneira virtual, não corpórea. Enquanto a gente ainda tiver pessoas negras que se sentem subjugadas por serem quem são; enquanto nós tivermos pessoas negras que não se sentem pertencentes, que não se sentem valorosas por serem que são; enquanto eu ainda odiar um corpo que nunca me fez nada, porque a sociedade diz que devo odiar; enquanto eu achar que a única coisa que me valoriza é um ideal racista, imposto sobre mim, quando meu corpo ainda nem havia se desenvolvido; enquanto isso acontecer, a senzala ainda é aqui. A senzala ainda é agora. E a chibata, mesmo que de maneira muito silenciosa, continua açoitando as nossas mentes. Obrigada. (Grifo nosso).

Neri termina sua apresentação nos trazendo uma reflexão sobre a senzala ainda ser aqui, e nossas mentes serem açoitadas pelas chibatas dos capitães do mato, ou seja, quando o Brasil é "vendido como o país do futebol, carnaval e da bunda", estamos vendendo os negros que outrora eram escravizados nas senzalas. O que dizem a nosso respeito é o reflexo ainda do período colonial. O vídeo de Nátaly Neri nos provoca a pensarmos sobre as novas senzalas, que reafirmam um estereótipo no imaginário racista brasileiro, seja através da "mulata Globeleza" ou de tantas outras mulheres negras expostas como mercadoria dentro e fora do sambódromo; Luísa segue nos informando sobre sua trajetória de vida: Eu não queria ter filho com 17 anos. Eu queria desfilar no carnaval... Mas eu não tomava remédio, acabei engravidando. Conheci o pai dos meus primeiros filhos lá na escola onde eu estudava e ele trabalhava. Quando eu engravidei, tive que parar os estudos e só voltei muito depois. Ele era casado, então só ficava lá em casa às vezes. Se eu não tivesse engravidado, acho que eu era passista até hoje. Mas eu me encantei por ele, antes dele virar alcoólatra, ele era muito bonito. Desde pequena eu sonhava em namorar um homem branco de cabelo liso, porque de morena com cabelo duro já bastava eu. Eu sofri muito na minha infância. Na minha escola ninguém queria ser minha amiga, porque minha mãe fazia umas tranças feias no meu cabelo. Eu só não 
sofria mais que a "preta muito preta", uma menina pretinha da outra classe, mais escura que eu. Os meninos até cuspiam nela!

Ao ouvir Luísa narrar sobre sua infância, com questões intimamente ligadas a construção da identidade negra dela, que influenciaram nas suas escolhas e nas suas relações, Dandara, se lembrou da criança negra que ela foi, que por vezes questionou a cor de pele e a textura do cabelo. Alguém que à medida que crescia, desejava mais e mais clarear com o passar dos anos. Mas, os anos foram passando, e a cor dela permaneceu: “preta”! Desde o seu período de escolarização, algumas lacunas não foram preenchidas, porque muitas vezes suas professoras não sabiam como lidar com questões relacionadas às crianças não-brancas. Esse desejo de embranquecer nunca foi só dela, assim como o de ser aceita também não era, desde crianças as populações negras são tratadas com inferioridade. Refletindo acerca da vida, a filósofa estadunidense, Judith Butler (2015) nos chama atenção para o absurdo que é, certos "enquadramentos epistemológicos" que qualifica quais são as vidas que podem ser consideradas vidas e quais são, ou seja, quais serão vividas e quais serão perdidas, no sentido pleno dessas palavras.

Nós não nascemos primeiro e em seguida nos tornamos precários; a precariedade é coincidente com o próprio nascimento (o nascimento é, por definição, precário), o que quer dizer que o fato de uma criança sobreviver ou não é importante, e que sua sobrevivência depende do que poderíamos chamar de uma "rede social de ajuda". É exatamente porque um ser vivo pode morrer que é necessário cuidar dele parra que possa viver. Apenas em condições nas quais a perda tem importância o valor da vida aparece efetivamente (p.32).

A condição precária da vida nos impõe uma obrigação, devido ao nosso corpo está exposto as forças articuladas social e politicamente, e a autora continua nos informando que:

Devemos nos perguntar em que condições torna-se possível apreender uma vida, ou um conjunto de vidas, como precária, e em que condições isso se torna menos possível ou mesmo impossível. É claro, não se deduz daí que se alguém apreende uma vida como precária decidirá protege-la ou garantir as condições para sua sobrevivência e prosperidade (p. 15-16). 
Essa precariedade que é coincidente com o próprio nascimento, desde cedo já potencializa a violência, sobretudo para as mulheres negras, onde em muitos casos a violência é antes, durante e/ou depois do nascimento. A pesquisadora Jackeline Aparecida Romio (2018), nos alerta que "o feminicídio está crescendo entre as mulheres negras e indígenas, embora esteja diminuindo entre as mulheres brancas", e defende a criação de políticas de segurança e saúde específicas para essas populações, tendo identificado "três tipos de feminicídio: sexual, doméstico e reprodutivo". Ela nos chama atenção para essas vidas que já vem lutando e tentando ser aceitas desde o ventre, quando a cor da pele, infelizmente, já determina o atendimento que receberão. $\mathrm{O}$ racismo institucional não dá trégua e o estereótipo racista torna essa vida um "corpo público" ainda na infância. As vidas que conseguem sobreviver, lutam para permanecerem vivas e terem dignidade.

\section{CONSIDERAÇÕES FINAIS}

Nesses encontros semanais, com muitos conflitos, tensões e negociações, com assuntos diversos, sendo o mais recorrente sobre os processos de descobertas que elas faziam juntas, Dandara e Luisa se deram conta que a medida que conversavam, refletiam sobre questões que no primeiro momento pareciam individuais, mas ao decorrer das conversas era nítido o quão coletivo eram os atravessamentos. Neste prisma, a mulher negra sempre teve o corpo público, exposto e vulnerável a hipersexualização, causando assim muitas vezes auto-ódio (como visto anteriormente) sendo impedida/desestimulada de estabelecer plenos laços afetivos. A respeito, bell hooks (2006) nos diz que,

A prática de se reprimir os sentimentos como estratégia de sobrevivência continuou a ser um aspecto da vida dos negros, mesmo depois da escravidão. Como o racismo e a supremacia dos brancos não foram eliminados com a abolição da escravatura, os negros tiveram que manter certas barreiras emocionais. E, de uma maneira geral, muitos negros passaram a acreditar que a capacidade de se conter emoções era uma característica positiva. No decorrer dos anos, a habilidade de esconder e mascarar os sentimentos passou a ser considerada como sinal de uma personalidade 
forte. [...] Normalmente as crianças aprendiam a não chorar quando eram espancadas. [...] E se tantas crianças negras aprenderam desde cedo que expressar as emoções é sinal de fraqueza, como poderiam estar abertas para amar? Muitos negros tem passado essa ideia de geração a geração: se nos deixarmos levar e render pelas emoções, estaremos comprometendo nossas sobrevivência. (p. 189-190, grifo nosso).

Esse trabalho, é parte de uma pesquisa em andamento, que narra experiências interseccionais cotidianas através de algumas narrativas - relatos de experiências - de mulheres negras e periféricas que ocorreram em encontros presenciais e virtuais, nos mostram histórias que ao longo do percurso trazem pertencimento e emancipação, e também, novos questionamentos. Se observarmos atentamente o nosso passado, facilmente entenderemos o presente e suas múltiplas histórias. O que bell hooks (2006) chama atenção, é justamente para que sejamos mais sensíveis ao que nos foi roubado/impedido de vivenciar nas nossas relações, sobretudo com os nossos corpos e os nossos pares. Essas histórias são atravessas por experiências que não podem em hipótese alguma serem desconsideradas e/ou sobrepostas, são diferenças que nos mostram que histórias importam!

Nesse sentido, este trabalho traz reflexões acerca do protagonismo de mulheres negras e dos diferentes processos identitários, visto que esses encontros proporcionam trocas de conhecimentos, afetos e alteridade, oportunizando-nos repensar o quão importante são esses espaços formativos, as redes e as representatividades negras que ocupam esses locais. Afinal, permite-nos aprofundar os estudos e as possibilidades de se pensar nos corpos negros e periféricos e nas (des)construções das sexualidades, principalmente no contexto brasileiro, historicamente pautado pela branquitude com a hipersexualização desses corpos desde a infância.

\section{REFERÊNCIAS}

ARRAES, Jarid. Heroínas negras brasileiras: em 15 cordéis. São Paulo: Pólen, 2017. ISBN: 978-85-983-4945-9.

BUTLER, Judith. Quadro de guerra. Quando a vida é passível de luto? Rio de Janeiro: Civilização Brasileira, 2015, p. 13-53. 
CRENSHAW, Kimberle Williams A Intersecionalidade na discriminação de raça e gênero. In: VV.AA. Cruzamento: raça e gênero. Brasília: Unifem, 2004. Disponível em: $<$ http://www.acaoeducativa.org.br/fdh/wp-content/uploads/2012/09/KimberleCrenshaw.pdf $>$. Acesso em: 01 abr. 2019.

DAVIS, Angela. Mulheres, raça e classe. $1^{a}$ edição, São Paulo: Boitempo, 2016.

EXAME. Mercado dos sex shops segue em alta. Disponível em: <https://exame.abril.com.br/negocios/mgapress/mercado-dos-sex-shops-segue-em-alta/>. Acesso em: 16 jul. 2019.

FANON. Frantz. Pele negra, máscaras brancas. Salvador: EDUFBA, 2008.

FERNANDES, Lygia de Oliveira. "Não falo do lugar dos derrotados": O encontro de saberes e suas potencialidades emancipatórias. 2019. Tese (Doutorado em Educação) Programa de Pós-Graduação em Educação, Universidade do Estado do Rio de Janeiro, Rio de Janeiro, 2019.

FRANCO, Marielle. A emergência da vida para superar o anestesiamento social frente à retirada de direitos: o momento pós-golpe pelo olhar de uma feminista, negra e favelada. In: Winnie Bueno, Joanna Burigo, Rosana Pinheiro-Machado, Esther Solano. (Org.). Tem Saída? Ensaios críticos sobre o Brasil. Porto Alegre: Editora Zouk, 2017, p. 89-95. ISBN: 978-858049-058-9. Disponível em: < http://www.editorazouk.com.br/Capitulo-MarielleFranco.pdf_>. Acesso em: 01 jul. 2019.

HOOKS, bell. Vivendo de amor. In: WERNECK, Jurema. (Org). O livro da saúde das mulheres negras: nossos passos vem de longe. $2^{a}$ edição, Rio de Janeiro: Pallas/Criola, 2006, p. 188-198. ISBN 85-87137-03-4.

PACHECO, Ana Cláudia Lemos. "Branca para casar, mulata para f.... e negra para trabalhar": escolhas afetivas e significados de solidão entre mulheres negras em Salvador, Bahia. (Tese de Doutorado, Universidade Estadual de Campinas, 2008).

PASSOS, Mailsa Carla Pinto. Encontros cotidianos e a pesquisa em Educação: relações raciais, experiência dialógica e processos de identificação. In: Educar em Revista. Curitiba: Editora UFPR, n. 51, jan./mar. 2014, p. 227-242. Disponível em: <https://revistas.ufpr.br/educar/article/view/33398/22082>. Acesso em: 05 jul. 2019.

RIBEIRO, Djamila. O que é lugar de fala?. Belo Horizonte: Letramento, 2017. ISBN 978-859530-040-8. 
ROMIO, Jackeline Aparecida. Feminicídio cresce entre mulheres negras e indígenas e diminui entre brancas, aponta pesquisadora. In: Câmara dos Deputados. Disponível em: < https://www2.camara.leg.br/camaranoticias/noticias/DIREITOS-HUMANOS/565155-

FEMINICIDIO-CRESCE-ENTRE-MULHERES-NEGRAS-E-INDIGENAS-E-DIMINUI-

ENTRE-BRANCAS,-APONTA-PESQUISADORA.html>. Acesso em: 20 mai. 2019.

SANTOS, Sônia Beatriz dos. Feminismo Negro Diaspórico. Revista Gênero, Niterói: UFF, n.1, v. $8, \quad 2^{\circ} \quad$ sem. 2007, p. 11-26. Disponível em: < http://www.revistagenero.uff.br/index.php/revistagenero/article/view/157>. Acesso em: 30 mar. 2019.

SOUZA, Claudete Alves da Silva. A solidão da mulher negra: sua subjetividade e seu preterimento pelo homem negro na cidade de São Paulo. (Dissertação de Mestrado, Pontifícia Universidade Católica de São Paulo, São Paulo, 2008).

SOUZA, Neusa Santos. Tornar-se negro. 2a edição, Rio de Janeiro: Graal, 1983. 